\title{
Kronik Fiziksel Hastalıkı Yaşlılarda Yeti Yitimi ve Depresyon
}

\author{
Disability and Depression among The Elderly People with Chronic Physical \\ Disease
}

\author{
Havva TEL*, Büşra Nur TAY**, Mehtap CANBAY**, İlknur AKAYA**, Sibel YALÇINKAYA**
}

İletişim/Correspondence: Havva TEL Adres/Address: Cumhuriyet Üniversitesi Sağlık Bilimleri Fakültesi Hemşirelik Bölümü-Sivas Tel:0 34621910 39-3157 Fax: 03462191261 E-mail: havvatelerciyes.edu.tr

\begin{abstract}
$\ddot{O} Z$
Amaç: Bu araştırma kronik fiziksel hastalık tanısı olan yaşlllarda yeti yitimi ve depresif belirtileri belirlemek amacı ile yapıldl. Yöntem: Tanımlayıcı nitelikteki bu araştırmaya kronik fiziksel hastalık tanısı ile bir üniversite hastanesinde tedavi alan 65 yaş ve üzeri 303 yaşlı birey alındı. Araştırma verileri kişisel bilgi formu, Kısa Yeti Yitimi Anketi ve Geriatrik Depresyon Ölçeği ile toplandl.

Bulgular: Kronik hastalıkl yaşlılarda yaş ile yeti yitimi ve yeti yitimi ile depresif belirtiler arasında anlamlı bir ilişki olduğu, yaş arttıkça yeti yitiminin arttı̆̆ , yeti yitimi arttıkça depresif belirti puanlarının arttı̆̆ belirlendi. Kadın, okuryazar olmayan ve günlük yaşam aktivitelerini sürdürmede bağımlı olan yaşlıların yeti yitimi ve depresif belirti puanlarının yüksek olduğu, dul yaşlıların yeti yitimi puanının yüksek, 65-70 yaş grubunda ve ekonomik durumu yüksek yaşlıların yeti yitimi puanlarının düşük olduğu saptandl.

Sonuç: Kronik fiziksel hastalıklı yaşlılarda yeti yitimi ile depresif belirti düzeyleri yakından ilişkilidir. Yaşlllarda yeti yitimi arttıkça depresif belirtiler de artmaktadır. Bu nedenle kronik fiziksel hastalıkl yaşlıların tedavi ve bakımında yeti yitimi ve depresyon belirtilerinin rutin olarak değerlendirilmesi yeti yitimi ve depresif belirtilerin bireyin yaşamı üzerindeki etkilerini önlemeye veya azaltmaya yönelik girişimlerin gerçekleştirilmesine yardım edecektir.
\end{abstract}

Anahtar Kelimeler: Yaşlı birey, kronik hastallk, yeti yitimi, depresyon.

\section{ABSTRACT}

Aim: The study was performed in order to explore the status of disability and depression among the elderly people diagnosed with chronic physical diseases.

Method: This descriptive study included 303 elderly individuals aged $65 \geq$ years who received treatment at a university hospital due to the diagnosis of a chronic physical disease. The data of the study were gathered using questionnaire form, Brief Disability Questionnaire and Geriatric Depression Scale.

Results: It was found out that there was a significant correlation between age and disability; and disability and depressive symptoms among the elderly people with a chronic disease and that as age increased so did disability and as disability increased so did depressive symptoms. It was noted that scores of disability and depressive symptom of the elderly people who were female, illiterate and dependent in order to continue activities of daily living were high whereas that scores of disability of those who belonged to 65-70 age group and high economic status were low. Widow's scores of disability were high.

Conclusion: Disability and depressive symptoms are closely interrelated among the elderly people with chronic physical diseases. As the disability increases so do depression signs among the elderly people. Therefore; in terms of providing treatment and care for the elderly people with a chronic disease, evaluation of disability and depressive symptom status will be helpful in realizing interventions to prevent or to decrease the effects of disability and depression upon the lives of the individuals.

Key Words: Elderly people, chronic disease, disability, depression.

\footnotetext{
* Prof. Dr. Cumhuriyet Üniversitesi Săglık Bilimleri Fakültesi Hemşirelik Bölümü, ** Öğrenci Cumhuriyet Üniversitesi Sağllk Bilimleri Fakültesi Hemşirelik Bölümü
}

Yazının gönderilme tarihi: 18.01.2013

Yazının basım için kabul tarihi: 11.04.2014 


\section{GíRiş}

Yaşl1l1k normal, biyolojik ve evrensel bir olgudur. Doğumda beklenen yaşam süresinin uzamasiyla dünya nüfusu yaşlanmaktadır. Dünyada 2020 yılında bir milyardan fazla yaşlı nüfus olacağı ve bunların çoğunun da ülkemiz gibi gelişmekte olan ülkelerde olacağı beklenmektedir (Canbaz, Sunter, Dabak ve Peksen 2003; Meisheri 1992). 2012 yılı verilerine göre ülkemizde 5.7 milyon yaşlı birey olduğu ve nüfusun \%7.5'ini oluşturduğu, 2023 yılında bu sayının 8.6 milyon olacağ1 ve toplam nüfusa oranın ise $\% 10,2$ 'ye yükseleceği belirtilmektedir (TUİK 2013). Yaşlılık döneminde bireylerde birçok kronik hastalık görülmektedir. Kronik hastalık bireyin yaşamının her alanını uzun süre etkileyen ve nükslerle devam eden önemli bir sağlık sorunudur (Garrett 1997). Ülkemizde 65 yaş ve üzerindeki bireylerin \%90'ında en az bir kronik hastalık olduğu belirtilmektedir (DBT 2001; Terakye ve Güner 1997). Yaşl1lık ve yaşl1lıkta görülen kronik hastalıklara bağlı olarak yaşlı bireylerde öz bakımı sürdürmede yetersizlik, günlük yaşam aktivitelerini yerine getirememe, başkalarına bağımlılık düzeyinde artma görülmekte, bireyler farklı düzeyde yeti yitimi yaşamaktadır (Çivi ve Tanrıkulu 2000). Yeti yitimi, bir etkinliği kişi için normal kabul edilen sınırlarda veya biçimde yapabilme yetisinde bir kisitlanma ya da kayıp olarak tanımlanmakta (WHO 1980) ve bireyin beden yapıs1 ve işlevlerinde bozukluklara bağlı olarak günlük yaşam aktivitelerinin sınırlanması sonucu ortaya çıkmaktadır. Yeti yitimi bireyin bağımsızlığını doğrudan etkilediğinden bireyin kendini başkalarına bağımlı, işe yaramaz hissetmesine, benlik saygısının düşmesine ve depresyona neden olabilmektedir (Boult, Kane, Louis, Boult ve McCaffrey 1994; Meerding, Bonneux, Polder, Koopmanschap ve Van der Maas 1998).

Depresyon yaşlık döneminde sık görülen, bireyin günlük yaşamını sürdürmesinde önemli aksamalara ve ciddi düzeyde yeti yitimine neden olan ruhsal bir hastalıktır. Yaşın ilerlemesi ile birlikte fiziksel yeteneklerde azalma, bilişsel işlevlerde gerileme, günlük aktivitelerini sürdürmede ve sosyal ilişkilerde zayıflama, ekonomik durumda kötüleşme, bireyin yalnız yaşama-
S1, sosyal destek sistemlerinin zayıf olması gibi etkenler yaşlılarda depresyon görülme sıklığını artırmaktadır (Çivi ve Tanrıkulu 2000; Steffens ve ark. 2000). Yapılan çalışmalarda yaşlılarda depresyon yaşama durumunun \%24 ile \%72 arasında değiştiği belirlenmiştir (Hacıhasanoğlu ve Türkleş 2008; Maral ve ark. 2001). Toplumun farklı kesimlerindeki yaşlılarda ise; evde yaşayan yaşl1ların \%15 ile \%25'inde, uzun dönem bakım merkezinde yaşayan yaşlıların \%25'inde, huzurevinde kalan yaşl1ların \%30'unda depresyon olduğu belirlenmiştir (Elopoulos 2005; Mavandadi ve ark. 2007). Kronik hastalıklar bireyde yeti yitimine nede $\mathrm{n}$ olmakla birlikte depresyon da bireyi çok yönlü etkilediğinde önemli düzeyde yeti yitimine neden olduğu görülmektedir. Literatürde yaşlılarda depresyonla ilgili birçok çalışma olmakla birlikte yaşlılarda depresyon ve yeti yitiminin birlikte ele alındığı çalışmaya rastlanmamıştır. Kronik hastalıklı yaşlılarda depresyon ve yeti yetimine ilişkin bilgiler depresyona bağ11 yeti yitimini önlemeye ve azaltmaya yönelik koruyucu, iyileştirici girişimlerin seçilmesine, yaşlı sağl1ğının geliştirilmesine katkı sağlayacaktır. Bu araştırma, kronik fiziksel hastalık tanısı olan yaşlı hastalarda yeti yitimi ve depresif belirtileri belirlemek amacıyla yapılmıştır.

\section{YÖNTEM}

\section{Araştırmanın Tipi}

Araştırma tanımlayıcı araştırma tipinde gerçekleştirilmiştir.

\section{Araştırmanın Yeri ve Zamanı}

Araştırma bir üniversitesi hastanesinde tedavi olan yaşlı hastalarla 11 Kasım 2009-11 Şubat 2010 tarihleri arasında gerçekleştirilmiştir.

\section{Araştırmanın Evreni ve Örneklemi}

Araştırmanın evrenini bir üniversitesi hastanesinde kronik fiziksel hastalık tanısı ile tedavi alan, 65 yaş ve üzeri hastalar oluşturmuştur. Örneklemini ise, 65 yaş ve üzerinde olan, kronik fiziksel hastalık tanısı ile tedavi alan, herhangi bir ruhsal ve nörolojik sorunu ol- 
mayan, görme, işitme kaybı gibi iletişim engeli olmayan ve araştırmaya katılmayı kabul eden 303 yaşlı birey oluşturmuştur.

\section{Verilerin Toplanması}

Araştırma verileri kişisel bilgi formu, kısa yeti yitimi ölçeği ve geriatrik depresyon ölçeği ile toplanmıştır. Veri toplama araçları çalışmaya katılmayı kabul eden yaşlı bireylerle yüz-yüze görüşme yoluyla uygulanmiştır.

Kişisel Bilgi Formu: Bireyin sosyo-demografik özellikleri ve kronik fiziksel hastalık sürecine ilişkin bilgileri araştıran; yaş, cinsiyet, medeni durum, eğitim durumu, meslek, gelir düzeyi, aile tipi, birlikte yaşadığ kişiler, hastalık süresi, hastalığın günlük yaşımını etkileyip- etkilemediği, günlük yaşam aktivitelerini yerine getirmede bağımlılık düzeyi gibi açık uçlu sorulardan oluşmuştur.

Kısa Yeti Yitimi Anketi (KYA): KYA 1988 yılında Stewart ve arkadaşları tarafindan fiziksel ve sosyal yeti yitimi durumunu değerlendirmek için geliştirilmiştir (Stewart, Hays ve Ware 1988). KYA’nın ülkemizde geçerlik ve güvenirlik çalışması Kaplan tarafından 1995 yılında yapılmıştır. KYA 11 sorudan oluşmaktadır. Ölçekten alınacak puanlar 0-22 arasında değişmektedir. Yeti yitimi puanları; 0-4 puan yeti "yitimi yok", 5-7 puan "hafif düzey yeti yitimi", 8-12 puan "orta düzeyde yeti yitimi”, 13 ve üzeri puan "ağır düzeyde yeti yitimi” olarak değerlendirilmektedir (Kaplan 1995; Stewart, Hays, Ware 1988).

Geriatrik Depresyon Ölçeği (GDÖ): GDÖ 1983 y1lında Yesavage ve ark. (1983) tarafından yaşlılarda depresyon taraması yapmak amacıyla geliştirilmiştir. Ö1çeğin ülkemizde geçerlik ve güvenirlik çalışması Ertan ve ark. (1997) yılında yapılmıştır. GDÖ’nun yaşlılar için uygulaması ve skorlaması kolay bir ölçek olduğu belirtilmektedir. Ölçek öz bildirime dayalı 30 sorudan oluşmakta ve ölçekteki her bir madde "evet" ve " hayır” şeklinde işaretlenmektedir. Ölçeğin değerlendirmesi; 0-10 puan "depresyon belirtisi yok", 11-13 puan "olası depresyon” 14 puan ve üzeri "kesin dep- resyon" şeklinde yapılmaktadır (Ertan, Eker ve Şar 1997; Yesavage ve ark. 1983).

\section{Araştırmanın Etik Yönü}

Araştırmaya başlamadan önce yazılı kurum izni alınmıştır. Araştırmaya katılmayı kabul eden yaşlılara araştırma hakkında bilgi verilerek sözel onamları alınmıştır.

\section{Verilerin Değerlendirilmesi}

Araştırma verileri bilgisayar ortamında SPSS 15.00 programında değerlendirmiştir. Verilerin analizinde tanımlayıcı istatistikler kullanılmıştır. Yaş ile yeti yitimi ve yetimi yitimi ile depresyon arasındaki ilişkinin belirlenmesinde Pearson korelasyon analizi kullanılmıştır. Yaşlıların sosyo-demografik özellikleri ve kronik fiziksel hastalık sürecine ilişkin özeliklerine göre yeti yitimi ve depresyonun değerlendirilmesinde $t$ testi ve ANOVA varyans analizi, gruplar arası karşılaştırma Tukey testi kullanılmıştır.

\section{BULGULAR}

Çalışmaya katılan yaşı hastaların; yaş ortalamasının $72.43 \pm 6.00$ (65-93) olduğu, \%44.55'inin 0-5 y1llık hastalık süresi olduğu, \%80.5'inin hastalığının günlük yaşamını etkilediği, \%95.4'ünün sürekli ilaç kullandığ1 saptanmıştır.

Tablo 1'de yaşlıların tanıtıcı özellikleri görülmektedir. Yaşlıların \%43.9'unun 65-70 yaş grubunda, \%51.8'inin kadın, \%65.3'ünün evli olduğu, \%53.5' inin okuma-yazma bilmediği, \%61.4'ünün orta düzeyde geliri olduğu, \%65.7'sinin çekirdek ailede yaşadığ1, \%58.7'sinin günlük yaşa aktivitelerinde bağımsız olduğunu ifade ettiği, \%42.6'sında ağır düzeyde yeti yitimi, \%59.7'sinde kesin depresyon belirtisi olduğu saptanmıştır.

Yaşlıların yaşı ile yeti yitimi ve yeti yitimi ile depresif belirtiler arasındaki ilişkiye bakıldığında, yaş ile yeti yitimi arasında $(r=.159, \mathrm{p}=.005)$ ve yeti yitimi ile depresif belirti puanları arasında $(r=.399, \mathrm{p}=.000)$ pozitif bir ilişki olduğu yaş arttıkça yeti yitiminin ve yeti yitimi arttıkça depresif belirtilerin arttığı belirlenmiştir. 
Tablo 1. Yaşlıların Tanıtıcı Özellikleri

\begin{tabular}{|l|ll|}
\hline Tanıtıcı Özellikler & Sayı & \% \\
\hline Yaş & & \\
65-70 & 133 & 43.9 \\
$71-75$ & 75 & 24.8 \\
$76-80$ & 65 & 21.5 \\
81 ve üzeri & 30 & 9.8 \\
\hline Cinsiyet & & \\
Kadın & 157 & 51.8 \\
Erkek & 146 & 48.2 \\
\hline Medeni durum & & \\
Evli & 198 & 65.3 \\
Dul & 105 & 34.7 \\
\hline Ĕgitim durumu & & \\
Okuryazar değil & 162 & 53.5 \\
Okuryazar & 48 & 15.8 \\
İlkokul & 72 & 23.8 \\
Ortaokul & 13 & 4.3 \\
Lise & 8 & 2.6 \\
\hline Ekonomik durum & & \\
Düşük & 88 & 29.0 \\
Orta & 186 & 61.4 \\
Yüksek & 29 & 9.6 \\
\hline Aile tipi & & \\
Çekirdek & 181 & 59.7 \\
\hline Geniş & 199 & 65.7 \\
\hline Günlük yaşam aktivitelerinde & & \\
Bağımsız & 178 & 58.7 \\
Yarı bağımlı & 103 & 34.0 \\
Bağımlı & 22 & 7.3 \\
\hline Yeti yitimi düzeyi & & \\
Yok & 30 & 9.9 \\
Hafif & 41 & 13.5 \\
Orta & 103 & 34.0 \\
Ağır & 129 & 42.6 \\
\hline Depresyon düzeyi & \\
Depresyon yok & & \\
Olası depresyon & & \\
Kesin depresyon & & \\
\hline & & \\
\hline
\end{tabular}

Tablo 2'de yaşlıların tanıtıcı özellikleri ile yeti yitimi ve depresif belirti puanları karşılaştırılmıştır. Yaşlı bireylerin yaş grubu, medeni durum, aile tipi ve ekonomik duruma göre yeti yitimi puanları arasında istatistiksel olarak anlamlı bir fark olduğu $(\mathrm{p}<0.05), 65-70$ yaş grubunda, çekirdek ailede yaşayan ve ekonomik durumunun yüksek olduğunu ifade eden yaşlıların yeti yitimi puanının düşük, dul yaşlıların yeti yitimi puanlarının yüksek olduğu saptanmıştır. Yaşlıların cinsiyet, eğitim durumu ve günlük yaşam aktivitelerini sürdürme özelliklerine göre yeti yitimi ve depresif belirti pu-
Tablo 2. Yaşlıların Tanıtıcı Özellikleri ile Yeti Yitimi ve Depresyon Puanlarının Karşılaştırılması

\begin{tabular}{|c|c|c|}
\hline $\begin{array}{l}\text { Tanıtıcı } \\
\text { Özellikler }\end{array}$ & $\begin{array}{l}\text { Yeti Yitimi } \\
x \pm \text { SD }\end{array}$ & $\begin{array}{c}\text { Depresif Belirti } \\
x \pm \text { SD }\end{array}$ \\
\hline $\begin{array}{l}\text { Yaş } \\
65-70 \\
71-75 \\
76-80 \\
81 \text { ve üzeri }\end{array}$ & $\begin{array}{l}11.05 \pm 5.60 \\
12.90 \pm 5.42 \\
12.89 \pm 5.77 \\
12.66 \pm 5.37\end{array}$ & $\begin{array}{l}14.99 \pm 3.10 \\
15.22 \pm 3.55 \\
15.41 \pm 3.13 \\
15.73 \pm 3.16\end{array}$ \\
\hline $\mathrm{F}, \mathrm{p}$ & $\mathrm{F}=2.624 \mathrm{p}=0.050$ & $\mathrm{~F}=0.551 \mathrm{p}=0.648$ \\
\hline $\begin{array}{l}\text { Cinsiyet } \\
\text { Kadin } \\
\text { Erkek }\end{array}$ & $\begin{array}{l}12.97 \pm 5.67 \\
11.08 \pm 5.41\end{array}$ & $\begin{array}{l}15.93 \pm 2.98 \\
14.43 \pm 3.30\end{array}$ \\
\hline $\mathrm{t}, \mathrm{p}$ & $\mathrm{t}=2.954 \mathrm{p}=0.003$ & $\mathrm{t}=4.148 \mathrm{p}=0.000$ \\
\hline $\begin{array}{l}\text { Medeni durum } \\
\text { Evli } \\
\text { Dul }\end{array}$ & $\begin{array}{l}11.40 \pm 5.58 \\
13.30 \pm 5.49\end{array}$ & $\begin{array}{l}14.90 \pm 3.29 \\
15.79 \pm 3.01\end{array}$ \\
\hline$t, p$ & $\mathrm{t}=7.984 \mathrm{p}=0.005$ & $\mathrm{t}=5.199 \mathrm{p}=0.23$ \\
\hline $\begin{array}{l}\text { Eğitim durumu } \\
\text { Okuryazar değil } \\
\text { Okuryazar } \\
\text { İlkokul } \\
\text { Ortaokul } \\
\text { Lise }\end{array}$ & $\begin{array}{c}13.32 \pm 5.61 \\
11.91 \pm 5.30 \\
9.87 \pm 4.73 \\
10.38 \pm 6.89 \\
9.87 \pm 6.44\end{array}$ & $\begin{array}{l}15.93 \pm 3.15 \\
14.91 \pm 3.14 \\
14.31 \pm 3.12 \\
13.76 \pm 3.19 \\
12.87 \pm 2.41\end{array}$ \\
\hline $\mathrm{F}, \mathrm{p}$ & $\mathrm{F}=5.712 \mathrm{p}=0.000$ & $\mathrm{~F}=5.513 \mathrm{p}=0.000$ \\
\hline $\begin{array}{l}\text { Ekonomik } \\
\text { durum } \\
\text { Düşük } \\
\text { Orta } \\
\text { Yüksek }\end{array}$ & $\begin{array}{c}13.38 \pm 5.15 \\
11.90 \pm 5.57 \\
9.10 \pm 6.15\end{array}$ & $\begin{array}{l}15.84 \pm 3.23 \\
15.04 \pm 3.16 \\
14.37 \pm 3.36\end{array}$ \\
\hline $\mathrm{F}, \mathrm{p}$ & $\mathrm{F}=6.783 \mathrm{p}=0.001$ & $\mathrm{~F}=2.918 \mathrm{p}=0.06$ \\
\hline $\begin{array}{l}\text { Aile tipi } \\
\text { Çekirdek } \\
\text { Geniş }\end{array}$ & $\begin{array}{l}11.54 \pm 5.56 \\
13.06 \pm 5.62\end{array}$ & $\begin{array}{l}14.98 \pm 3.25 \\
15.65 \pm 3.12\end{array}$ \\
\hline $\mathrm{t}, \mathrm{p}$ & $\mathrm{t}=-2.257 \mathrm{p}=0.025$ & $\mathrm{t}=1.720 \mathrm{p}=0.086$ \\
\hline $\begin{array}{l}\text { Günlük yaşam } \\
\text { aktivitelerinde } \\
\text { bağımlılık } \\
\text { düzeyi } \\
\text { Bağımsız } \\
\text { Yarı bağımlı } \\
\text { Bağımlı } \\
\end{array}$ & $\begin{array}{c}9.54 \pm 4.67 \\
15.25 \pm 4.63 \\
17.54 \pm 5.54\end{array}$ & $\begin{array}{l}14.61 \pm 3.31 \\
15.91 \pm 2.95 \\
16.77 \pm 2.58\end{array}$ \\
\hline $\mathrm{F}, \mathrm{p}$ & $\begin{array}{c}\mathrm{F}=63.482 \\
\mathrm{p}=0.000\end{array}$ & $\mathrm{~F}=8.426 \mathrm{p}=0.000$ \\
\hline
\end{tabular}

anları arasında istatistiksel olarak anlamlı bir fark oldugu $(p<0.05)$, Yeti yitimi ve depresif belirti puanlarının kadın ve okur-yazar olmayan yaşlilarda ilkokul mezunu yaşlılardan daha yüksek, günlük yaşam aktivitelerini sürdürmede bağımsız olanlarda bağımlı ve yarı bağımlı olanlardan daha düşük olduğu saptanmıştır. 


\section{TARTIŞMA}

Yaşl1lık bireyin fiziksel görünüm, rol ve bulunduğu konum açısından kayba uğradığı, yeti yitimleri ve fiziksel hastalıkların artarak bireyin çevreye bağımlı hale geldiği bir dönemdir (Tamam ve Öner 2001). Kronik fiziksel hastalığı olan yaşlılarda yeti yitimi ve depresif belirtilerin araştırıldığı bu çalışmada yaş ile yeti yitimi ve yeti yitimi ile depresif belirtiler arasında pozitif bir ilişki olduğu, yaş arttıkça yeti yitiminin arttığı, yeti yitimi arttıkça da depresif belirtilerin arttığı saptanmıştır. Yapılan çalışmalarda yaşlanma sürecinde ortaya ç1kan yeti yitiminin birey, aile ve toplumu çok yönlü etkilediği belirtilmektedir (Boult, Kane, Louis, Boult ve McCaffrey 1994). Fiziksel hastalıklarda yeti yitimi fiziksel sınırlılık nedeniyle yaşanırken, fiziksel hastalık ve ruhsal sorunların bir arada olduğu durumda yeti yitimi birçok alanda yaşanmaktadır (Dewa ve Lin 2000; Druss ve ark. 2000). Kronik hastaliklarda ruhsal bozukluklar ve buna bağlı yeti yitimi sağlıklı nüfusa k1yasla oldukça yüksek oranda görülmektedir (Dewa ve Lin 2000; Weyerer, Hewer, Pfeifer-Kurda ve Dilling 1998). Kronik hastalığı olan yaşlılarda depresyon daha s1k görülmektedir (Gomez ve Gomez 1993; Hacıhasanoğlu ve Türkleş 2008; Maral ve ark. 2001). Kronik fiziksel hastalık ve ruhsal hastalığın bir arada olduğu durumlarda yeti yitiminin daha da arttığ1, depresyon tan111 bireylerin \%67.2'sinde yeti yitimi olduğu saptanmıştır (Stewart ve ark. 1989). Depresyonun önemli yeti yitimlerine neden olduğu, yaşam kalitesini azalttığı fiziksel hastalığın gidişini olumsuz yönde etkilediği, intihar ve fiziksel hastalıklara bağlı ölümleri artırdığg, sağlık, bakım gibi hizmetlerin kullanımını ve maliyetini artırdığı belirtilmektedir (Göktaş ve Özkan 2006; Steffens ve ark. 2000). 65-70 yaş grubundaki yaşlıların yeti yitimi puanının düşük, dul ve ekonomik durumu düşük yaşların yeti yitimi puanlarının yüksek olduğu saptanmıştır. Verbrugge ve Jette (1994) dul yaşlıların büyük çoğunluğunda yeti yitimi olduğunu belirlemiştir (Verbrugge ve Jette 1994). Akın ve Emiroğlu (2003) sürekli aylık geliri olmayan yaşlılarda yeti yitiminin yüksek olduğunu saptamıştır. Mevcut çalışmanın bulguları bu sonuçlarla benzerlik göstermektedir.
Yaşlıların cinsiyet, eğitim durumu ve günlük yaşam aktivitelerini sürdürme özelliklerine göre yeti yitimi ve depresif belirti puanları arasında istatistiksel olarak anlamlı bir fark olduğu $(\mathrm{p}<0.05)$, kadın, okur-yazar olmayan, günlük yaşam aktivitelerini sürdürmede bağımlı olan yaşlıların yeti yitimi ve depresif belirti puanlarının yüksek olduğu saptanmıştır. Yapılan çalışmalarda yeti yitimi ve depresyonda kadın olmak, yalnız yaşıyor olmak, dul veya boşanmış olmak, günlük yaşam aktivitelerinde başkalarına bağımlı olmak gibi psikososyal etkenlerin ve kronik hastalıkların etkili olduğu belirlenmiştir (Göktaş ve Özkan 2006; Tamam ve Öner 2001). Ayrıca Akın ve Emiroğlu (2003) yaşlı kadınların büyük çoğunluğunda yeti yitimi olduğunu, Guralnik, Ferrucci, Simonsick, Salive, Wallace (1995) yeti yitimi olan yaşlılarda günlük yaşam aktivitelerinde bağımlılık düzeyinin yüksek olduğunu belirlemiştir. Mevcut çalışma bulguları bu sonuçlarla uyumludur.

Depresyonun yetişkin dönemde olduğu gibi yaşlılık döneminde de kadınlarda erkeklere göre daha fazla görüldüğü, depresyonun eğitim ve gelir düzeyi düşük bireylerde daha sık görüldüğü belirtilmektedir (Beekman, Copeland ve Prince 1999). Zunzunegui, Beland, Llacer ve Leon (1998) 65 yaş üstü yaşlı kadınlarda depresyon oranını \%46, erkeklerde \%20 olarak belirlemiştir. Kadın olmanın depresyonda temel bir risk etkeni olduğu, kadınların biyolojik yapısı, ruhsal özellikleri, kişilik yapıs1, sorunlarla başa çıkma biçimi, toplumsal ve kültürel konumu gibi faktörlerin depresyonda etkili olabileceği bildirilmektedir (Güz, Yaman ve Dilbaz 2007; Ünal ve Özcan 2000). Dişçigil, Gemalmaz, Başak, Gürel ve Tekin (2005) eğitim durumu düşüklüğünün depresyon için bir risk faktörü olduğunu, Tamam ve Öner (2001) günlük yaşam aktivitelerinde başkalarına bağımlı olmanın yaşlılık döneminde depresyon için önemli risk faktörlerinden biri olduğunu bildirmektedir.

\section{SONUÇ VE ÖNERILER}

Kronik fiziksel hastalıklı yaşlılarda yeti yitimi ve depresif belirtilerin değerlendirildiği bu çalışmada; yaş arttıça yeti yitiminin artmakta, yeti yitimi ile birlikte depresif belirtilerde artmaktadır. 65-70 yaş grubun- 
daki yaşlıların yeti yitimi puanının düşük, dul ve ekonomik durumunun düşük olduğunu ifade eden yaşların yeti yitimi puanlarının yüksek olduğu, kadın, okuryazar olmayan, günlük yaşam aktivitelerini sürdürmede bağımlı olan yaşlıların yeti yitimi ve depresif belirti puanlarının yüksek olduğu saptanmıştır. Yaşlıların fiziksel hastalık tanısı ayrımı olmaksızın hastanede yatan yaşlılarla yapılması araştırmanın sınırlı yönüdür. Araştırmadan elde edilen sonuçlar doğrultusunda kronik fiziksel hastalıklı yaşlıların tedavi ve bakımında;

- Bireylerin yeti yitimi ve depresif belirtilerinin değerlendirilmesi,

- Yeti yitimi ve depresif belirtilerin bireyin yaşamı üzerindeki etkilerini önleme veya azaltmaya yönelik planlamaların yapılması,

- Okuma-yazma bilmemek yaşlının kendini ifade etmesinde önemli bir engel olduğu için çevre ile iletişimde yetersizliklere neden olabilmektedir. $\mathrm{Bu}$ nedenle yaşlı bireylere tedavi ve bakımı ile ilgili sürekli ve düzenli bilgi verilmesi,

- Yaşlı hastaların sağlık personelinden yardım ve destek almaya cesaretlendirilmesi,

- Günlük yaşam aktivitelerinde bağımlı olmak yeti yitimi ve depresyon için önemli bir risk faktörü olduğundan yaşlı bireylerin günlük yaşam aktivitelerini sürdürmede desteklenmesi,

- Yaşlıların fiziksel hastalık tanılarına göre yeti yitimi ve depresif belirtilerini değerlendiren araştırmalar yapılması önerilmektedir.

\section{KAYNAKLAR}

Akın, B., Emiroğlu, N. (2003). Evde yaşayan yaşlilarda mobilitede yetiyitimi ve ilişkili faktörlerin incelenmesi. Türk Geriatri Dergisi, 6(2): 59-67.

Beekman, A. T., Copeland, J. R., Prince, M. J. (1999). Review of community prevalence of depression in later life. Br J Psychiatry, 174: 307-311.

Boult, C., Kane, R. L., Louis, T. A., Boult, L., McCaffrey, D. (1994). Chronic conditions that lead to functional limitation in the elderly. J Gerontol., 49(1): 28-36.

Canbaz, S., Sunter, A. T., Dabak, S., Peksen, Y. (2003). The prevalence of chronic diseases and quality of life in elderly people in Samsun. Turk. J Med. Sci., 33(5): 335-340.
Çivi, S., Tanrıkulu, Z. (2000). Yaşlılarda bağımlılık ve fiziksel yetersizlik düzeyi ile kronik hastalık prevalansını saptamaya yönelik çalışma. Türk Geriatri Dergisi, 3(3): 85-90.

Dewa, C. S., Lin, E. (2000). Chronic physical illness, psychiatric disorder and disability in the workplace. Soc Sci Med., 51(1): 4150 .

Diş̧̧igil, G., Gemalmaz, A., Başak, O., Gürel, S., Tekin, N. (2005). Birinci basamakta geriatrik yaş grubunda depresyon. Türk Geriatri Dergisi, 8(3): 129-133.

Devlet Planlama Teşkilatı (DPT) (2001). Sekizinci Beş Yıllık Kalkınma Planı-Sağlık Hizmetlerinde Etkinlik Özel İhtisas Komisyonu Raporu. Ankara.

Druss, B. G. ve ark. (2000). Understanding disability in mental and general medical conditions. Am J Psychiatry, 157(9): 14851491.

Elopoulos, C. (2005). Gerontological Nursing. 6th. ed., Lippincott Williams\&Wilkins, Philedephia.

Ertan, T., Eker, E., Şar, V. (1997). Geriatrik Depresyon Ölçeği’nin Türk yaşlı nüfusunda geçerlilik ve güvenirliliği. Nöropsikiyatri Arşivi, 34(2): 62-71.

Garrett, M. J. (1997). Chronic conditions. Black, J. M., Jacobs, E. M. (Eds.). Medical-Surgical Nursing. W.B. Saunders Company, Philadelphia,105-106.

Gomez, G. E., Gomez, E. A. (1993). Depression in the elderly. $J$ Psychosocl Nurs Ment Health Serv., 31(5): 28-33.

Göktaş, K., Özkan, İ. (2006). Yaşl1larda depresyon. Türkiye'de Psikiyatri, 8(1): 30-37.

Guralnik, J. M., Ferrucci, L., Simonsick, E. M., Salive, M. E., Wallace, R. B.(1995). Lower-exstremity function in persons over the age 70 years as a predictor of subsequent disability. $N$ Engl J Med., 332(9): 556-561.

Güz, H., Yaman, M. A., Dilbaz, N. (2007). Fiziksel hastalığı olan yaşlılarda depresyon ve diğer psikiyatrik belirtiler. Türkiye'de Psikiyatri, 9(1): 44-49.

Hacıhasanoğlu, R., Türkleş, S. (2008). Depression and affecting factors in the old age at the age of 65 and over. Atatürk Üniversitesi Hemşirelik Yüksekokulu Dergisi, 11(2): 55-60.

Kaplan, İ. (1995). Yarı kırsal alanda bir sağlık ocağına başvuran hastalarda ruhsal bozuklukların yetiyitimi ile ilişkisi. Türk Psikiyatri Dergisi, 6(3): 169-79.

Maral, I. ve ark. (2001). Depresyon yaygınlığı ve risk etkenleri: Huzurevinde ve evde yaşayan yaşlılarda karşılaştırmalı bir çalışma. Türk Psikiyatri Dergisi, 12(4): 251-260. 
Mavandadi, S., ve ark. (2007). Effect of depression treatment on depressive symptoms in older adulthood: The moderating role pain. J Am Geriatr Soc., 55(2): 202-211.

Meerding, W. J., Bonneux, L., Polder, J. J., Koopmanschap, M. A., Van der Maas, P. J. (1998). Demographic and epidemiological determinants of health care cost in Netherlands: Cost of illness study. BMJ., 317(7151): 111-115.

Meisheri, Y. V. (1992). Geriatric services-need of the hour. J Postgrad Med.,38(39): 103-105.

Steffens, D. C. ve ark. (2000). Prevalence of depression and its treatment in an elderly population: The Cache County study. Arch Gen Psychiatry, 57(6): 601-607.

Stewart, A. L., Hays, R. D., Ware, J. E. J. Jr. (1988). The MOS Short-form general health survey. Reliability and validity in patient population. Med Care., 26(7): 724-735.

Stewart, A. L., ve ark. (1989). Functional status and well-being of patients with chronic conditions, results from the medical outcomes study. JAMA, 262(7): 907-913.

Tamam, L., Öner, S. (2001). Yaşlılık çağı depresyonları. Demans Dergisi, 1(2): 50-60.

Terakye, G., Güner, P. (1997). Kriz potansiyeli taşıyan bir dönem: Yaşl11ı. Kriz Dergisi, 5(2): 95-101.
Ünal, S., Özcan, E. (2000.) Depresyonda hazırlayıcı, ortaya ç1karıcı ve koruyucu etkenler. Anadolu Psikiyatri Dergisi, 1(1): 41-45.

TUIK (2013). Nüfus projeksiyonları, 2013-2075: Türkiye İstatistik Kurumu Haber Bülteni, http:// www.tuik.gov.tr/PreHaberBultenleri (06.09.2013).

Verbrugge, L. M., Jette, A. M. (1994). The disablement process. Soc Sci Med., 38(1): 1-14.

Weyerer, S., Hewer, W., Pfeifer-Kurda, M., Dilling, H. (1989). Psychiatric disorders and diabetes results from a community study. J Psychosom Res., 33(5): 633-640.

World Healt Organization (WHO) (1980). International Classification of Impairments, Disabilities and Handicaps: A Manuel of Classification Relating to the Consequences of Disease, Cenevre.

Yesavage, J. A. ve ark. (1983). Development and validation of a geriatric depression screening scale: A preliminary report. J. Psychiatr Res., 17(1): 37-49.

Zunzunegui, M. V., Beland, F., Llacer, A., Leon, V. (1998). Gender difference in depressive symptoms among Spanish elderly. Soc Psychiatry Psychiatr Epidemiol., 33(5): 195-205. 